\title{
PENERAPAN MODEL PEMBELAJARAN GUIDED INQUIRY MELALUI METODE RESITASI TERHADAP HASIL BELAJAR PESERTA DIDIK
}

\author{
Hikmah 1,a, Dewi Sartika ${ }^{2, b}$ \\ Universitas Sulawesi Barat \\ email: hikmahfisika@unsulbar.ac.id, bdewi.sartika@unsulbar.ac.id
}

\begin{abstract}
Abstrak
Penelitian ini bertujuan untuk mengetahui hasil belajar peserta didik model pembelajaran inquiry terbimbing dengan metode resitasi, dan perbedaan yang signifikan hasil belajar peserta didik antara kedua kelas. Metode yang digunakan dalam penelitian ini adalah pra-eksperimen dengan desain One Group Pretest-Posttest. Populasi dalam penelitian ini adalah seluruh peserta didik kelas X SMA Negeri 1 Pamboang. Sampel yang diteliti adalah kelas X IPA 2 sebanyak 32 orang yang dipilih dengan teknik simple random sampling. Instrumen pengumpulan data berbentuk tes hasil belajar. Data dianalisis dengan menggunakan analisis deskriptif, inferensial, dan uji N-Gain. Penelitian menunjukkan bahwa hasil belajar peserta didik meningkat setelah diterapkan model pembelajaran inkuiri terbimbing dengan metode resitasi. Terdapat perbedaan yang signifikan terhadap hasil belajar fisika peserta didik kelas $X$ IPA 2 SMA Negeri 1 Pamboang tahun pelajaran 2015/2016 sebelum dan setelah diajar dengan menerapkan metode resitasi melalui model pembelajaran Guided inquiry.
\end{abstract}

Kata kunci: Model pembelajaran inkuiri terbimbing, Metode resitasi, Hasil belajar

\section{APPLICATION OF THE GUIDED INQUIRY LEARNING MODEL THROUGH RESITATION METHOD ON STUDENTS' LEARNING OUTCOMES}

\begin{abstract}
This study aims to determine student learning outcomes guided inquiry learning model with the recitation method, and the significant difference in student learning outcomes between the two classes. The method used in this research is pre-experiment with One Group Pretest-Posttest design. The population in this study were all students of class X SMA Negeri 1 Pamboang. The sample studied was class X IPA 2 as many as 32 people who were selected by simple random sampling technique. The data collection instrument is in the form of a learning outcome test. Data were analyzed using descriptive, inferential, and $\mathrm{N}$-Gain tests. The research shows that student learning outcomes increase after the guided inquiry learning model is applied with the recitation method. There is a significant difference in the physics learning outcomes of students in class XIPA 2 at SMA Negeri 1 Pamboang in the 2015/2016 academic year before and after being taught by applying the recitation method through the Guided inquiry learning model.
\end{abstract}

Keywords: Guided inquiry learning model, Recitation method, Learning outcomes

\section{PENDAHULUAN}

Mata pelajaran fisika seharusnya menjadi suatu pelajaran yang diminati dan disenangi oleh peserta didik. Namun pada kenyataannya secara umum rata-rata hasil belajar peserta didik pada mata pelajaran fisika masih rendah. Demikian halnya yang terjadi di SMA Negeri 1 Pamboang. kelas X IPA 2 hasil belajar fisika peserta didik masih rendah. Hal ini terlihat dari rata-rata hasil belajar peserta didik yang belum mencapai ketuntasan dengan nilai rata-rata sebesar 60 , sementara nilai tersebut dikatakan belum optimal karena masih dibawah standar nilai KKM yang ditetapkan di SMA Negeri 1 pamboang yaitu 70. 
Salah satu teknik pengajaran yang dianggap sesuai dalam mengasah hasil belajar peserta didik yaitu dengan menerapkan model pembelajaran inkuiri terbimbing melalui metode resitasi. Metode Resitasi (penugasan) adalah penyajian bahan dimana guru memberikan tugas tertentu agar siswa melakukan kegiatan belajar. Misalnya tugas yang dilaksanakan oleh siswa dapat dilakukan dalam kelas, halaman sekolah, perpustakaan, masjid atau dimana saja asalkan tugas tersebut dikerjakan, kemudian tugas tersebut dipertanggungjawabkan kepada guru.

Guided inquiry bertujuan untuk memaksimalkan proses pembelajaran. Guided inquiry merupakan model pembelajaran yang menekankan pada proses berpikir secara kritis dan analitis untuk mencari dan menemukan sendiri jawaban dari suatu masalah yang dipertanyakan. Pernyataan ini sejalan dengan Indri Elyani pada tahun 2011 dalam penelitiannya bahwa metode pembelajaran inkuiri berpengaruh terhadap peningkatan hasil belajar fisika [1], serta pernyataan ini pula didukung oleh hasil penelitian Nita Nurtafita pada tahun 2011 yang menyimpulkan bahwa terdapat pengaruh metode resitasi terhadap hasil belajar, dikarenakan penggunaan metode resitasi menekankan peran serta siswa dalam kegiatan pembelajaran [2].

Inkuiri adalah istilah dalam bahasa inggris inquiri yang berarti pertanyaan, pemeriksaan, atau penyelidikan. Pendekatan inkuiri berarti suatu rangkaian kegiatan belajar yang melibatkan secara maksimal seluruh kemampuan siswa untuk mencari dan menyelidiki secara sistematis, logis,kritis analisis, sehingga mereka dapat merumuskan sendiri penemuannya dengan penuh percaya diri [3].

Inquiry learning adalah belajar mencari dan menemukan sendiri. Dalam sistem belajar mengajar ini guru menyajikan bahan pelajaran tidak dalam bentuk yang final, tetapi anak didik diberi peluang untuk mencari dan menemukannya sendiri dengan menggunakan teknik pendekatan pemecahan masalah [4]. Adapun langkah-langkah yang perlu diikuti dalam pembelajaran inkuiri terbimbing adalah orientasi, merumuskan masalah, merumuskan hipotesis mengumpulkan data, menguji hipotesis, dan merumuskan kesimpulan [5].

Berdasarkan latar belakang dan hasil wawancara di SMA Negeri 1 Pamboang, dengan peserta didik mereka mengakui bahwa fisika itu pelajaran yang sangat susah, karena selalu dihiasi dengan persamaan-persamaan sehingga dihadapkan antara menghafal rumusrumus dan berhitung sehingga cenderung membosankan. Oleh karena itu, diperlukan suatu pembelajaran yang mampu meningkatkan keterampilan peserta didik dalam memahami pelajaran serta membuat peserta didik lebih aktif dalam belajar fisika dan mengoptimalkan peserta didik dalam menyelesaikan soal-soal. Salah satu upaya untuk mengetahui hasil belajar khususnya pada mata pelajaran fisika yaitu dengan menerapkan suatu model pembelajaran yang dapat mengasah hasil belajar peserta didik. Upaya melatih hasil belajar dapat dilakukan salah satunya dengan penerapan model pembelajaran guided inquiry (inquiri terbimbing) melalui metode resitasi.

\section{METODE}

Penelitian ini menggunakan jenis penelitian pra-Eksperimen (pre-eksperimental Design). Menggunakan desain "One Group Pretest-Posttest".

\section{$\begin{array}{lll}\mathrm{O}_{1} & \mathrm{X} & \mathrm{O}_{2}\end{array}$}

Populasi dalam penelitian ini adalah seluruh peserta didik kelas X SMA Negeri 1 Pamboang. Sampel yang diteliti adalah kelas X IPA 2 sebanyak 32 orang yang dipilih dengan teknik simple random sampling. Instrumen yang digunakan dalam penelitian ini adalah instrumen tes yaitu berupa tes hasil belajar dalam bentuk tes pilihan ganda. Analisis pada setiap item menggunakan rumus $\gamma_{p b_{i}}$ sebagai berikut:

$$
\gamma_{p b_{i}}=\frac{M_{p}-M_{t}}{s_{t}} \sqrt{\frac{p}{q}}
$$

Uji reliabilitas ini dilakukan untuk mengetahui apakah instrumen yang digunakan dalam penelitian ini dapat dipercaya sebagai alat pengumpul data. Untuk menghitung reliabilitas tes dapat digunakan rumus KuderRichardson (KR-20), yaitu sebagai berikut:

$$
r_{11}=\left(\frac{n}{n-1}\right)\left(\frac{s^{2}-\sum p q}{s^{2}}\right)
$$

Data yang dikumpulkan dalam penelitian ini adalah data hasil belajar. Pengumpulan data dilakukan melalui dua tahap yaitu pre-test dan post-test. Data tersebut dianalisis dengan menggunakan teknik analisis 
deskriptif dan analisis inferensial. Rumus yang digunakan dalam analisis deskriptif untuk penelitian ini adalah sebagai berikut:

Menghitung rata-rata $(\bar{X})$

$\bar{X}=\frac{\sum x_{i}}{n}$

Standar Deviasi (S)

$S=\sqrt{\frac{\sum\left(x_{i}-\bar{x}\right)^{2}}{n-1}}$

Pengubahan skor hasil belajar ke bentuk nilai persentase dihitung dengan menggunakan rumus sebagai berikut:

Skor $=\frac{\text { jumlah skor }}{\text { skor maksimal }} \times 100 \%$

Pengujian normalitas yang digunakan pada penelitian ini adalah dengan metode ChiKuadrat. Rumus yang digunakan adalah sebagai berikut:

$\chi^{2}=\sum_{i=1}^{k} \frac{\left(f_{0}-f_{h}\right)^{2}}{f_{h}}$

Pengujian hipotesis yang dilakukan adalah uji statistik parametrik yaitu menggunakan uji t. Rumus yang digunakan adalah :

$t=\frac{M d}{\sqrt{\frac{\Sigma X^{2} d}{N(N-1)}}}$

Uji N-Gain menunjukkan kategori peningkatan hasil belajar fisika peserta didik. Rumus N-Gain (Meltzer, 2002):

Gain $=\frac{\text { skor posttest-skor pretest }}{\text { skor idel-skor pretest }}$
[11]

\section{HASIL DAN DISKUSI \\ Analisis Deskriptif Hasil Belajar \\ Hasil Data Pretest}

Data hasil belajar fisika peserta didik kelas X IPA 2 SMA Negeri 1 Pamboang tahun ajaran 2015/2016 setelah diberikan pretest dapat dilihat pada tabel di bawah ini.

Tabel 1. Hasil Pengolahan Data Hasil Belajar Fisika Peserta Didik Kelas X IPA SMA Negeri 1 Pamboang pada Pretest

\begin{tabular}{lc}
\hline \multicolumn{1}{c}{ Statistik } & Pretest \\
\hline Ukuran sampel & 32 \\
Skor ideal & 20 \\
Skor tertinggi & 11 \\
Skor terendah & 2 \\
Skor rata-rata & 6,2 \\
Standar deviasi & 2,69
\end{tabular}

Sumber: hasil penelitian (data olahan)

Berdasarkan tabel data hasil belajar fisika diatas, menunjukkan bahwa skor tertinggi yang dicapai peserta didik yaitu 11 sedangkan skor terendahnya adalah 2 dari skor ideal 20. Adapun skor rata-rata yang diperoleh peserta didik adalah 6,2 dengan standar deviasi 2,69.

Data kategori hasil belajar fisika peserta didik pada pretest dapat disajikan dalam tabel berikut:

Tabel 2. Tabel Kategori hasil belajar fisika peserta didik pada Pretest

\begin{tabular}{|c|c|c|c|c|}
\hline \multirow[t]{2}{*}{ Interval Skor } & \multirow{2}{*}{$\begin{array}{c}\text { Interval } \\
\text { Nilai }\end{array}$} & \multicolumn{2}{|c|}{ Frekuensi } & \multirow[t]{2}{*}{ Kategori } \\
\hline & & Absolut & Relatif (\%) & \\
\hline $17-20$ & $81-100$ & 0 & 0 & Sangat Tinggi \\
\hline $14-16$ & $61-80$ & 0 & 0 & Tinggi \\
\hline $9-12$ & $41-60$ & 2 & 6.25 & Sedang \\
\hline $5-8$ & $21-40$ & 15 & 46.875 & Rendah \\
\hline $0-4$ & $0-20$ & 15 & 46.875 & Sangat Rendah \\
\hline \multicolumn{2}{|c|}{ Total } & 32 & 100 & \\
\hline \multicolumn{2}{|c|}{ Skor rata } & 6,2 & 26,4 & Rendah \\
\hline
\end{tabular}


Berdasarkan pada tabel di atas, dapat diketahui bahwa hasil belajar peserta didik pada mata pelajaran fisika setelah dilakukan pretest menunjukkan bahwa terdapat 15 peserta didik $(46,875 \%)$ berada pada kategori rendah, 15 peserta didik $(46,875 \%)$ berada pada kategori sangat rendah, 2 peserta didik $(6,25)$ berada pada kategori sedang dan tidak ada peserta didik yang berada pada kategori tinggi, dan sangat tinggi $(0 \%)$. Sedangkan persentase tertinggi berada pada interval 21 - 40 sebanyak 15 peserta didik $(46,875 \%)$ yang tergolong kategori rendah dan interval 0-20 sebanyak 15 peserta didik $(46,875 \%)$ berada pada kategori sangat rendah.

\section{Hasil Data Posttest}

Data hasil belajar fisika peserta didik kelas X IPA SMA Negeri 1 Pamboang tahun ajaran 2015/2016 setelah diberikan posttest dapat dilihat pada tabel di bawah ini.
Tabel 3 Hasil Pengolahan Data Hasil Belajar Fisika Peserta Didik Kelas X IPA SMA Negeri 1 Pamboang pada Posttest

\begin{tabular}{lc}
\hline \multicolumn{1}{c}{ Statistik } & Posttest \\
\hline Ukuran sampel & 32 \\
Skor ideal & 20 \\
Skor tertinggi & 17 \\
Skor terendah & 8 \\
Skor rata-rata & 13,5 \\
Standar deviasi & 2,69
\end{tabular}

Sumber: hasil penelitian (data olahan)

Berdasarkan tabel data hasil belajar fisika diatas, menunjukkan bahwa skor tertinggi yang dicapai peserta didik yaitu 17 sedangkan skor terendahnya adalah 8 dari skor ideal 20. Adapun skor rata-rata yang diperoleh peserta didik adalah 13,5 dengan standar deviasi 2,69.

Kategori hasil belajar fisika peserta didik kelas X IPA 2 SMA Negeri 1 pamboang pada posttest disajikan dalam tabel berikut:

Tabel 4. Tabel Kategori Hasil Belajar Fisika peserta didik pada Posttest

\begin{tabular}{ccccc}
\hline Interval Skor & Interval & \multicolumn{2}{c}{ Frekuensi } & Kategori \\
\cline { 3 - 4 } & Nilai & Absolut & Relatif $(\%)$ & \\
\hline $17-20$ & $81-100$ & 4 & 12.5 & Sangat Tinggi \\
\hline $14-16$ & $61-80$ & 18 & 56.25 & Tinggi \\
\hline $9-13$ & $41-60$ & 8 & 25 & Sedang \\
\hline $5-8$ & $21-40$ & 2 & 6.25 & Rendah \\
\hline $0-4$ & $0-20$ & 0 & 0 & Sangat Rendah \\
\hline \multicolumn{2}{c}{ Total } & 32 & 100 & \\
\hline \multicolumn{2}{c}{ Skor rata-rata } & 13,4 & 67,2 & tinggi \\
\hline \multicolumn{5}{c}{} \\
\end{tabular}

Berdasarkan pada tabel di atas, dapat diketahui bahwa hasil belajar peserta didik pada mata pelajaran fisika setelah dilakukan posttest menunjukkan bahwa terdapat 4 peserta didik $(12,5 \%)$ berada pada kategori sangat tinggi, 18 peserta didik $(56,25 \%)$ berada pada kategori tinggi, 8 peserta didik $(25 \%)$ berada pada kategori sedang, 2 peserta didik $(6,25)$ dan tidak ada peserta didik yang berada pada kategori sangat rendah $(0 \%)$. Sedangkan persentase tertinggi berada pada interval 61- 80 sebanyak 18 peserta didik $(56,25 \%)$ yang tergolong kategori tinggi.
Hasil pengujian normalitas data skor hasil belajar fisika peserta didik pada pretest menunjukkan bahwa nilai $X_{\text {hitung }}^{2}=4,34$. dan $X_{\text {tabel }}^{2}=11,1$ pada taraf nyata $\alpha=0,05 \mathrm{dan} \mathrm{dk}$ $=5$. Karena $X_{\text {hitung }}^{2}<X_{\text {tabel }}^{2}$ maka data skor hasil belajar fisika peserta didik pada pretest berdistribusi normal pada taraf nyata $\alpha=0.05$. Begitu pula dengan uji normalitas data skor hasil belajar fisika peserta didik pada posttest menunjukkan bahwa nilai $X_{\text {hitung }}^{2}=8,95$ dan $X_{\text {tabel }}^{2}=11,1$ pada taraf nyata $\alpha=0,05 \mathrm{dan} \mathrm{dk}$ 
=5. Dengan perolehan $X_{\text {hitung }}^{2}<X_{\text {tabel }}^{2}$ maka data skor hasil belajar fisika peserta didik pada posttest berdistribusi normal pada taraf nyata $\alpha=0.05$. Dengan demikian data skor hasil belajar fisika baik sebelum dan setelah diajar dengan menerapkan metode resitasi melalui model inquiry Learning berdistribusi normal dengan taraf nyata $\alpha=0.05$.

Hipotesis yang diuji dengan menggunakan uji $\mathrm{t}$ adalah " terdapat peningkatan yang signifikan terhadap hasil belajar fisika peserta didik kelas X IPA 2 SMA Negeri 1 Pamboang setelah diajar dengan menerapkan metode Resitasi melalui model Guided inquiry." Pada taraf nyata $\alpha=0,05$ dengan $\mathrm{dk}=5$ diperoleh $\mathrm{t}_{\text {tabel }}=1,7$ dan $\mathrm{t}_{\text {hitung }}=$ 4,92. Karena $t_{\text {hitung }}>t_{\text {tabel }}$ maka $\mathrm{H}_{0}$ ditolak dan $\mathrm{H}_{1}$ diterima artinya $\mathrm{H}_{0}$ ditolak dikarenakan tidak terdapat perbedaan skor hasil belajar peserta didik yang signifikan setelah diajar dengan menggunakan metode resitasi melalui model pembelajaran Guided inquiry dan $\mathrm{H}_{1}$ diterima dikarenakan terdapat perbedaan skor hasil belajar peserta didik yang signifikan setelah diajar dengan menggunakan metode resitasi melalui model pembelajaran Guided inquiry. Sehingga terdapat perbedaan yang signifikan terhadap hasil belajar fisika peserta didik kelas X IPA 2 SMA Negeri 1 Pamboang sebelum dan setelah diajar dengan menerapkan metode resitasi melalui model Guided inquiry.

\section{Uji N-Gain}

Hasil Uji N-Gain hasil belajar fisika peserta didik disajikan dalam tabel berikut ini.

Tabel 5 Distribusi Frekuensi Peningkatan konsep Peserta Didik Kelas X IPA 2 SMA Negeri 1 Pamboang Berdasarkan Rentang N-Gain

\begin{tabular}{ccc}
\hline Kategori & Frekuensi & Persentase (\%) \\
\hline Tinggi & 7 & 21.875 \\
\hline Sedang & 21 & 65.625 \\
\hline Rendah & 4 & 12.5 \\
\hline Jumlah & 32 & 100 \\
\hline Rata-rata N-Gain & $\mathbf{0 . 5 4}$ & sedang \\
\hline
\end{tabular}

Distribusi frekuensi peningkatan hasil belajar fisika berdasarkan rentang $\mathrm{N}$-Gain disajikan dengan menggunakan diagram batang berikut ini:

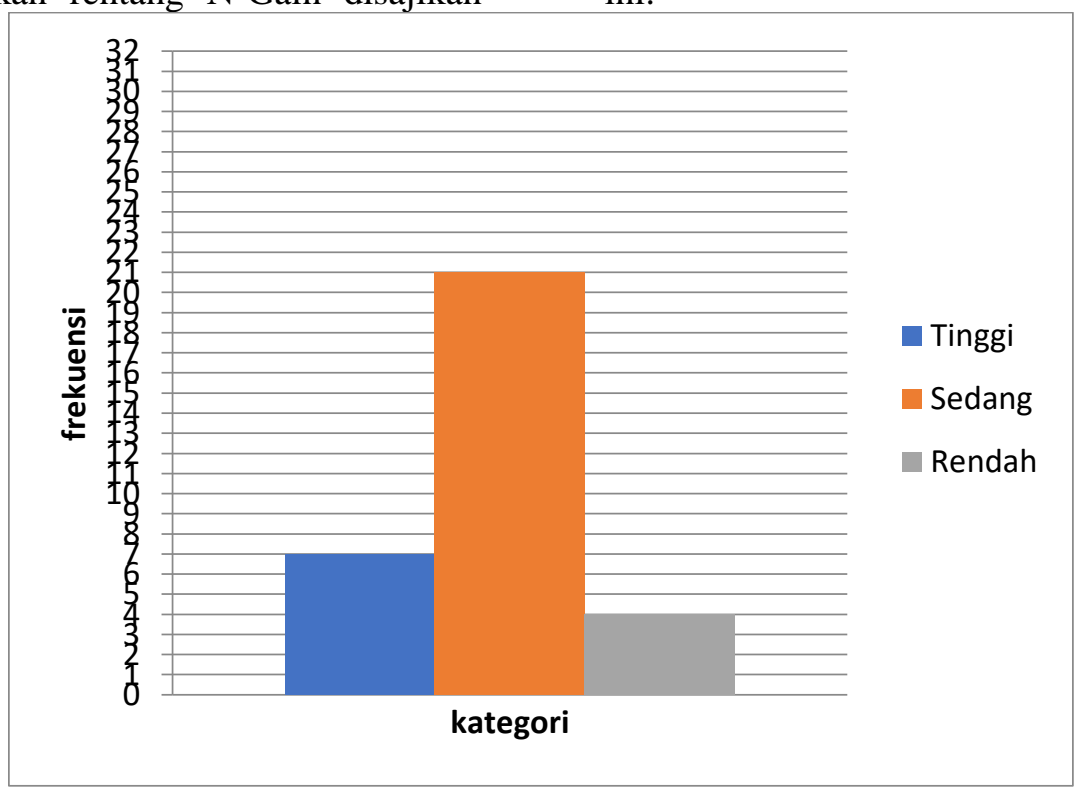

Gambar 1. Diagram batang kategori peningkatan hasil belajar fisika peserta didik 
Dari tabel distribusi peningkatan hasil belajar, diperlihatkan bahwa terdapat 7 peserta didik $(21,875 \%)$ memenuhi kriteria tinggi, 21 peserta didik $(65,625 \%)$ memenuhi kriteria sedang, dan 4 peserta didik (12,5\%) memenuhi kriteria rendah. Terlihat juga bahwa peserta didik kelas $X$ IPA 2 SMA Negeri 1 Pamboang memiliki skor rata-rata $\mathrm{N}$-gain sebesar 0,54 yang tergolong kategori sedang berdasarkan kategori rentang N-Gain.

\section{SIMPULAN DAN SARAN Simpulan}

Hasil belajar fisika peserta didik kelas $\mathrm{X}$ IPA 2 SMA Negeri 1 Pamboang tahun pelajaran 2015/2016 sebelum diajar dengan menerapkan metode resitasi melalui model pembelajaran Guided inquiry berada pada kategori rendah. Hasil belajar fisika peserta didik kelas X IPA 2 SMA Negeri 1 Pamboang tahun pelajaran 2015/2016 setelah diajar dengan menerapkan metode resitasi melalui model pembelajaran Guided inquiry berada pada kategori tinggi. Terdapat perbedaan yang signifikan terhadap hasil belajar fisika peserta didik kelas X IPA 2 SMA Negeri 1 Pamboang tahun pelajaran 2015/2016 sebelum dan setelah diajar dengan menerapkan metode resitasi melalui model pembelajaran Guided inquiry.

\section{Saran}

Sebaiknya jadwal pelajaran fisika dijadwalkan pada jam pertama agar peserta didik tidak mudah letih dan merasa bosan saat proses belajar berlangsung. Pada pertemuan pertama sebaiknya guru menyampaikan tata tertib yang dianggap dapat mengganggu proses pembelajaran berlangsung, agar masalah seperti yang dihadapi oleh peneliti tidak terjadi pada penelitian berikutnya. Diharapkan kepada guru agar menggunakan model atau metode yang bervariasi dalam proses pembelajaran. Penerapan metode resitasi melalui model pembelajaran Guided inquiry adalah salah satu model yang cocok untuk digunakan dalam meningkatkan proses belajar peserta didik.

\section{DAFTAR PUSTAKA}

[1] Indri Elyani. 2011. Pengaruh model pembelajaran inquiri terbimbing terhadap hasil belajar fisika pada konsep getaran dan gelombang, diakses http://www.inquiri.terbimbing.skripsi.com . pada tanggal 17 februari 2011
[2] Nurtafita, Nita. 2011. Pengaruh Metode Guided Inquiry Terhadap Keterampilan Proses Sains Siswa Pada Konsep Kalor. Skripsi Pendidikan Fisika Fakultas Ilmu Tarbiyah Dan Keguruan Universitas Islam Negeri Syarif Hidayatullah: Jakarta.

[3] Gulo, W. 2002 Strategi Belajar Mengajar. Jakarta: Gramedia

[4] Djumingin,Sulastriningsih. 2011. Strategi dan Aplikasi Model Pembelajaran Inovatif Bahasa dan Sastra. Makassar : Badan Penerbit UNM

[5] Jauhar, M. 2011. Implementasi PAIKEM Dari Behavioristik Sampai Kontruktivistik. Jakarta : Prestasi Pustakaraya

[6] Sugiyono. 2009. Metode Penelitian Pendidikan. Bandung : Alpabeta.Wates, Kulon Progo. Skripsi. Yogyakarta: Jurusan Pendidikan Pra Sekolah dan Sekolah Dasar Fakultas Ilmu Pendidikan

[7] Arikunto, Suharsimi. 2009. Dasar-dasar Evaluasi Pendidikan (Edisi Revisi).Jakarta : Bumi Aksara

[8] Sugiyono. 2013. Statistika untuk Penelitian. Bandung: Alfabeta

[9] Ali, \& Khaeruddin. 2012. Evaluasi Pembelajaran. Makassar: UNM

[10] Arikunto, Suharsimi. 2007. Dasar-dasar Evaluasi Pendidikan. Jakarta : Bumi Aksara.

[11] Richards. C.J. 1999. Towords Reflective Teaching The Teacher Trainer. Back articles Dalam Teacher trainer. 5 halaman. Tersedia: http://www.tttjournal.co.uk 3 Maret 2012 